\section{Doppelseitige reflektorische Pupillenstarre nach Schädeltrauma durch Granatenfernwirkung.}

Von Dr. Klemens Bergl,

1. Assistent der Doutschen Psychiatrischen Universitätsk]inik in l'rag, z. Z. k. u. k. Oberarzt i. Pelde.

Die große Seltenheit der reinen reflektorischen Pupillenstarre llach Scliädeltrauma veranlaßt mich, folgende auf dem südlichen Kriegsschauplatze gemachte Beobachtung mitzuteilen, zumal sie vermöge der Klarheit der Verhältnisse nicht bloß würdig dem einzigen als einwandfrei zu bezeichnenden Falle von Finkelnburg sich anreiht, sonderll diesen in mancher Hinsicht noch an Präzision ïbertrifft.

Infanterist Z. L. dus X. L..I.-R. wurde aul 12. Oktober 1914 verletzt. Sowcit seinc Angaben verwertbur sind - er crinncrt sich nicht gonau des ganzen Vorganges - cxplodierte in del Schwarmlinic ctwa 20 Sehritt vor ihın eine Granate, er wurde zwar von kcinem Sprengstück direkt getroffen, jedoch durch den Gasdruck ungefähr 15 Schritt weit fortgeschleudert, wo er bewußtlos licgen blieb. Er wurde erst nach mehreren Stunden auf den Verbandplatz geschafft, wo er nuch Wieder belebungsversuchen das BewuBtscin erlangte. Nach Angaben des ihn ins Reservespital begleitenden Sanitätssoldaten soll J'atient d('n ersten Tag erbrochen, die ganzc Zeit übcr Kopfschmerzen und zeitweise übcr Sohwindel geklagt haben. Außer goringfügigen Kontusionen an den Bcinen und unteren Rückenpartien waren an dem Mann keinerlei Effekto des Sturzes zu konstatiercil.

In Spital machte der Mann einen ausgesprochen schläfrigen Eindruck, lag ganz apathiseh, sich selten bewegend, iun Bett, sprach spontan garnichts, mußte die ersten Tage sogar gefüttert werden, ließ alles ohne Widerstreben nit sich goschehen, war aber rein und suchte allein das Klosett auf. Die ersten funf Tage war ein Fxanıen nit ihn fust ulmöglich, er war in Antworten, neist nach wicder-holter Fragestellung, bloB zu ,,ja" oder ,"lein" zu bewegen, gab abcr heftige Kopfschmerzen zu. Dic Erinnerung für das Trauma kchrte teilweise wieder, doch blicb sie für dic Zeit von del Explosion bis zur Einlieformng ins Spital sch lïckenhaft.

Befund: Ziemlich großer, nuskulöser, etwas magerer Mann An Schädel keine Spur irgendeiner Verletzung nachweisbar, der ganze Schädel etwas klopfenpfindlich. Augenbcfund (gleichzeitig uuch von Doz. Löwenstein, dem Assistenten unserer Augenklinik, crhoben) Visus 1, A ugenhintergrund nornal, Medien klar, Iris frei. Pupillen zien lich weit, gleich, rund; Reaktion auf Licht (Tageslicht, elektrische Lampe) beiderseits fehlend, auch die konsensuelle $R e$ aktion nicht auslösbar; dagegen ist die Reaktion bei Konvergenz und Akkommodation vorhanden, ausgiebig, vielleicht eine Spur verlangsamt. Die Augenbewegungen sind frei, geringer rotatorischer Nystagmus horizontalis. Konjunktivalreflexe nur auf kräftigere Reize auslösbar Kornealroflexe vorhanden. Gesichtsfeld bei der Unzugänglichkeit des Kranken schwer prüfbar, jedenfalls keine deutliche Finengung. Gaunen Rachenreflexe schwach. Facialis synmetrisch innerviert, Gehör ill takt. Zunge wird gerade vorgestreckt, zittert lebhaft. Kopfbewegungen

Die Beweglichkeit des Rumpfes und der Extremitäten ist frei, durch keinerlei Schmerzen behindert; als Restc des Sturzes finden sich an den Beinen, an den untcren Rückenparticn mchrere dunkelblaue Blutunterlaufungen, die nicht mehr schmerzhaft sind. Die Sehnen. reflexe der Arme lebhaft, Bauchdecken. und Kremasterreflexe vorhanden, Patellar- und Achillessehnenreflexe lebhaft, gleich, keinerle Klonus. Bei Stehen mit geschlossenen Augen auf schmaler Basis leichtes Schwanken, durch Aenderungen der Kopthaltung nicht irgendwie gesetzmäßig beeinflußbar. Die Zeigereaktionen pathologisch nicht verändert

Im Verluf der folgenden 14 Tage trat in dem Befinden des Kranken cine nur unwesentliche Besserung ein, insofern, als scine große Apathie schwand, er ein gewisses Inturesse an der Umgebung zu zeigen begann, was sich hauptsächlich darin zeigte, daß er zu den Menagezeiten das Bett verließ, sich zum Tisch, und zwar immer an denselben Platz be gab, sich ganz ordentlich bediente und aß. Spontan sprach er aber noch immer nichts, gab jedoch auf Fragen immerhin zusammenhängende Antworten, wenn auch sehr langsam und wortkarg. Die Lichtreaktion der Pupillen, die jodesmal bei den täglichen zwoi Visiten gonau geprïft wurde, änderte sich zunächst garnicht, erst am 4. November früh war eine Spur von Kontraktion zu bemerken und an Nachmittag dessclben
Tages war dic Reaktion ausgiebig, wenn auch noch ctwas träge, vorhanden. Sie wurde im Verlaufe der folgenden zwei Tage so gut wic normal, jedenfalls war in Verglcich zur Konvergenz und A kkommodations. reaktion keinerlei Unterschied in Ablauf und Ausmaß zu konstatieren auch dic konsensuelle lichtreaktion war wieder deutlich vorhanden.

Da sich das Befinden des Mannes in der nächsten Zeit nicht wcitcr besscrtc, hauptsächlich das deprinierte, etwas stumpf-apathische Wo*en unverändert blieb, wurde er in ein stabiles Spital im Hinterlande abtransportiert.

Finkelnburg stellt in seiner Arbeit bestimmte Bedingungen auf, unter welchen eine reflektorische Pupillenstarre als traumatische angesehen werden kann, und zwar Nacliweis normaler Pupillenfunktion vor oder unmittelbar nach dem Trauma; eine gewisse Schwere des Traumas, also Commotio oder Schädelbruch; geringer zeitlicher Abstand des Einsetzens der Pupillenstarre vom Zeitpunkte des Traumas; die Sicherheit des Fehlens einer luetischen Genese und längere Beobachtung, um eine durch das Trauma eventuell ausgelöste metaluetisehe Erkrankung ausschließen zú können.

Die Umstände, unter denen meine Beobachtung erfolgte, bringen es mit sich, daß diesen Forderungen nicht vollständig entsprochen werden konnte. Der Fall kam vier Tage nach dem Trauma zur Beobachtung mit voll entwickelter Pupillenstarre, während Konvergenz- und Akkommodationsreaktion der Norm entsprechend vorhanden waren. Die anamnestischen Daten gestatten, das Vorhandensein einer Commotio cerebri als erwiesen anzunehmen, wofür der gesamte Zustand des Kranken bei der Einlieferung eindeutig sprach, dagegen liegt kein Anhaltspunkt vor, der einen Schädelbruch anzunehmen gestattete. Die chemische, sero- und zytologische Untersuchung von Serum und Liquor konnte begreiflicherweise nicht vorgenommen werden, immerhin glaube ich Lues mit Bestimmt. heit ausschließen zu können. Es handelt sich um einen gesunden, kräftigen Landmann von 22 Jahren, der klinisch in keiner Beziehung auf Lues verdächtig ersoheint; überdies spricht das überraschend schnelle Verschwinden der Licht starre und die Wiederkehr der normalen Pupillenreaktion ziemlich eindeutig dagegen. Gerade dieses Moment ist es, das den vorliegenden Fall besonders wertvoll macht, denn bei der gegebenen Sachlage erscheint es ausgeschlossen, an einen der äußerst seltenen Fälle denken $z u$ wollen, bei dem im Verlaufe einer luetischen Zerebralerkrankung (noch dazu ohne jede spezifische Behandlung) die Pupillenstörung zeit. weise zurückgeht; bekanntlich ist eine solche Rückbildung auch niemals vollständig.

Der Sitz der Läsion dürtte im vorliegenden Falle sowie in dem von Finkelnburg in Bereiche des zentralen Reflexbogenteiles, im zentralen Höhlengrau des Aquaeductus Sylvii zu suchen sein.

Die Pupillenstarre aus einer Läsion des Zervikalmarkes zu erklären, wie dies in einem Falle Dreifuss zu tun versuchte, erscheint bei dem vorliegenden Falle ohne weiteres untunlich; ebensowenig spricht irgendein Symptom für die Annahme einer doppelseitigen Bulbuskontusion oder für eine Stammläsion des Oculomotorius - der in seinen übrigen Funktionen vollkommen ungestört erschien — wie dies bei dem Fall von A xenfeld beschrieben wird.

Auf die Frage nach der Natur der Läsion glaube ich als für unser Thema irrelevant nicht eingehen zu sollen; es ist klar, daß ebensosehr die Annahme einer kleinen Blutung wie die einer Kontusion, desgleichen auch eine funktionelle Läsion mit dem Verschwinden der gesetzten Störung in Einklang gebracht werden können und nichts hier eine zureichende Entscheidung in dieser Frage ermöglicht.

Literatur: Axenteld. D. m. W. 1906 S. 663 . - Finkelnburg, D. m. W. 1914 S. 1005. 